\title{
The 27-item Coping Strategies Questionnaire - Revised: Confirmatory factor analysis, reliability and validity in Italian-speaking subjects with chronic pain
}

\author{
Marco Monticone MD PhD ${ }^{1}$, Simona Ferrante $\mathrm{PhD}^{2}$, Ines Giorgi Psy ${ }^{3}$, \\ Caterina Galandra Psy ${ }^{3}$, Barbara Rocca Psy ${ }^{1}$, Calogero Foti $\mathrm{MD}^{4}$
}

\begin{abstract}
M Monticone, S Ferrante, I Giorgi, C Galandra, B Rocca, C Foti. The 27-item Coping Strategies Questionnaire - Revised: Confirmatory factor analysis, reliability and validity in Italian-speaking subjects with chronic pain. Pain Res Manag 2014;19(3):153-158.
\end{abstract}

BACKGROUND: Increasing attention is being devoted to cognitivebehavioural measures to improve interventions for chronic pain.

OBJECTIVE: To develop an Italian version of the Coping Strategies Questionnaire - Revised (CSQ-R), and to validate it in a study involving 345 Italian subjects with chronic pain.

METHODS: The questionnaire was developed following international recommendations. The psychometric analyses included confirmatory factor analysis; reliability, assessed by internal consistency (Cronbach's alpha) and test-retest reliability (intraclass correlation coefficients); and construct validity, assessed by calculating the correlations between the subscales of the CSQ-R and measures of pain (numerical rating scale), disability (Sickness Impact Profile - Roland Scale), depression (Center for Epidemiological Studies - Depression Scale) and coping (Chronic Pain Coping Inventory) (Pearson's correlation).

RESULTS: Confirmatory factor analysis revealed that the CSQ-R model had an acceptable data-model fit (comparative fit index and normed fit index $\geq 0.90$, root mean square error of approximation $\leq 0.08$ ). Cronbach's alpha was satisfactory (CSQ-R 0.914 to 0.961 ), and the intraclass correlation coefficients were good/excellent (CSQ-R 0.850 to 0.918). As expected, the correlations with the numerical rating scale, Sickness Impact Profile - Roland Scale, Center for Epidemiological Studies - Depression Scale and Chronic Pain Coping Inventory highlighted the adaptive and maladaptive properties of most of the CSQ-R subscales.

CONCLUSION: The CSQ-R was successfully translated into Italian. The translation proved to have good factorial structure, and its psychometric properties are similar to those of the original and other adapted versions. Its use is recommended for clinical and research purposes in Italy and abroad.

Key Words: Confirmatory factor analysis; Coping Strategies Questionnaire; Cross-cultural adaptation; Reliability; Validity

\author{
Le questionnaire révisé sur les stratégies \\ d'adaptation en 27 questions : l'analyse factorielle \\ confirmatoire, la fiabilité et la validité chez des \\ sujets de langue italienne souffrant de douleur \\ chronique
}

HISTORIQUE : On s'intéresse davantage aux mesures cognitivocomportementales pour améliorer les interventions pour contrer la douleur chronique.

OBJECTIF : Élaborer une version italienne du questionnaire révisé sur les stratégies d'adaptation (CSQ-R) et la valider auprès de 345 sujets italiens souffrant de douleur chronique.

MÉTHODOLOGIE : Le questionnaire a été élaboré en fonction de recommandations internationales. Les analyses psychométriques incluaient une analyse factorielle confirmatoire, la fiabilité, évaluée selon la cohérence interne (coefficient alpha de Cronbach) et la fiabilité test-retest (coefficients de corrélation intraclasse), ainsi que la validité conceptuelle, évaluée en calculant les corrélations entre les sous-échelles du CSQ-R et les mesures de la douleur (échelle d'évaluation numérique), l'incapacité (Sickness Impact Profile - échelle de Roland), la dépression (Center for Epidemiological Studies - échelle de dépression) et l'adaptation (inventaire d'adaptation à la douleur chronique) (corrélation de Pearson).

RÉSULTATS : L'analyse factorielle confirmatoire a révélé que le modèle du CSQ-R présentait une bonne adéquation des données empiriques (indice d'adéquation comparatif et indice d'adéquation normalisé minimal de 0,90 , erreur quadratique moyenne d'approximation 0,08). Le coefficient alpha de Cronbach était satisfaisant (CSQ-R 0,914 à 0,961), et les coefficients de corrélation intraclasse étaient bons à excellents (CSQ-R 0850 à 0,918). Comme prévu, les corrélations avec l'échelle d'évaluation numérique, le Sickness Impact Profile - échelle de Roland, le Center for Epidemiological Studies - échelle de dépression et l'inventaire d'adaptation à la douleur chronique ont fait ressortir les propriétés adaptives et maladaptives de la plupart des sous-échelles du CSQ-R.

CONCLUSION : Le CSQ-R a été traduit en italien avec succès. Il avait une bonne structure factorielle, et ses propriétés psychométriques sont semblables à celle de la version originale et des autres versions adaptées. Son utilisation est recommandée en clinique et en recherche, tant en Italie qu'à l'étranger.

The Coping Strategies Questionnaire (CSQ) was developed in 1983 by Rosenstiel and Keefe (3) using a pool of items reflecting coping strategies frequently reported by patients and deemed to be important by researchers and clinicians involved in the management of pain. Although it had good reliability and validity, it showed an unstable structure (3-5) that has been hypothesized to be mainly due to difficulties in measuring differences in cognition between different clinical settings, disorders and pain problems (6). In 1996, an exploratory factor analysis of a large sample of subjects with chronic pain suggested a six-factor solution that was relatively supportive of the original scales, and showed satisfactory reliability and construct validity (7). A subsequent confirmatory factor analysis (CFA) established the good fit of this model (ie, the CSQ-Revised) (8). chronic pain is physically disabled or invariably depressed; many continue their work and social activities, and rarely seek medical assistance or the help of a significant other (1). Therefore, it appears to be crucial to identify the cognitive factors that may promote adaptive functioning despite the presence of pain, such as coping strategies (ie, the use of cognitive and behavioural techniques to manage stressful events), because these can help to explain differences in adjustment among subjects experiencing chronic pain, determine cognitive strengths and weaknesses, identify treatment targets and predict outcomes (2).

${ }^{1}$ Physical Medicine and Rehabilitation Unit, Salvatore Maugeri Foundation IRCCS, Institute of Care and Research, Scientific Institute of Lissone;

${ }^{2}$ Neuroengineering and Medical Robotics Laboratory, Department of Electronics, Information, and Bioengineering, Politecnico di Milano,

Milan; ${ }^{3}$ Operative Unit of Psychology, Salvatore Maugeri Foundation, Institute of Care and Research, Scientific Institute of Pavia, Pavia;

${ }^{4}$ Physical Medicine and Rehabilitation, Tor Vergata University of Rome, Rome, Italy

Correspondence: Dr Marco Monticone, Via Monsignor Bernasconi 16, 20035 Lissone, Italy. Telephone 39-039-465-7277,

fax39-039-465-7279, e-mail marco.monticone@fsm.it 
Translations of the CSQ have been validated and allow comparisons among different populations and countries (9-11). However, the CSQRevised version has yet to be adapted and psychometrically analyzed in Italian subjects, thus limiting the opportunities for researchers and clinicians to share the validated outcomes of chronic pain patients.

The aim of the present study was to describe the cultural adaptation of the CSQ-Revised and its validation in a large sample of subjects with chronic pain to enable its use in Italian-speaking subjects in Italy and abroad. It was hypothesized that internal consistency would be acceptable, that test-retest reliability would be good, and that CSQRevised maladaptive coping strategies would be statistically significantly and positively related to poor outcomes of pain intensity, disability and depression. It was also expected that the CSQ-Revised adaptive and maladaptive strategies would be statistically significantly and positively related to adaptive and maladaptive strategies taken from another coping questionnaire, respectively.

\section{METHODS}

The present cross-sectional study was approved by the Institutional Review Board of the authors' hospital (Salvatore Maugeri Foundation's Scientific Institute, Lissone, Italy), and the patients provided written informed consent to participate.

\section{Subjects}

Outpatients attending the Rehabilitation and the Psychology Units of Salvatore Maugeri Foundation's Scientific Institute were recruited between January 2011 and September 2012. The inclusion criteria were: chronic nonspecific pain (ie, lasting continuously for $>3$ months); age $>18$ years; and fluency in Italian. The exclusion criteria were: acute (ie, lasting $<1$ month) and subacute (ie, lasting one to three months) nonspecific pain; central or peripheral neurological signs; systemic illness (eg, tumours and rheumatological diseases); and cognitive impairment (ie, deficits in higher reasoning, forgetfulness, learning disabilities, concentration difficulties, decreased intelligence and other reductions in mental functions). Patients who had experienced recent cerebrovascular accidents, myocardial infarctions, or chronic lung or renal diseases were also excluded.

The subjects' demographic and clinical characteristics were recorded by a research assistant using a specific form.

\section{CSQ-Revised}

This 27-item questionnaire measures the use of strategies for coping with pain by assessing six domains: Distraction; Catastrophizing; Ignoring pain sensations; Distancing from pain; Coping selfstatements; and Praying. Patients rate the frequency of their use of the specific strategies using a seven-point Likert scale ranging from 0 "Never do that" to 6 "Always do that"; each domain is scored separately, with higher scores indicating greater use (7). The original form was tested in English-speaking subjects and showed acceptable internal consistency (Cronbach's alpha estimates ranging from 0.72 to 0.86) and satisfactory construct validity - ie, maladaptive strategies, such as Catastrophizing and Praying, were positively associated with negative effects and negatively associated with the level of activity, whereas adaptive strategies, such as Ignoring pain sensations and Coping self-statements, were positively associated with the level of activity (7).

\section{Translation and cross-cultural adaptation}

This procedure was performed in accordance with international guidelines (12).

Step 1. Translation into Italian: The items derived from the English CSQ-Revised were translated with the aim of retaining the concepts of the original while using culturally and clinically fitting expressions (7). Two translators, whose first language was Italian, each independently translated the English version into Italian, keeping the language colloquial and compatible with a reading age of 14 years. One of the translators was unfamiliar with the measure. The translators then reviewed the two Italian versions together, ensuring that items with poor wording were identified and improved by means of discussion. Step 1 ended when a common adaptation was agreed on. None of the items were excluded.

Step 2. Back-translation into English: Two independent bilingual translators whose first language was English back-translated the initial translation; they did not have medical backgrounds and were unaware of the concepts being explored. The aim was to ensure the Italian version reflected the same item content as the original version and was conceptually equivalent.

Step 3. Expert committee: The translated versions were submitted to an expert committee of bilingual (Italian and English speaking) clinicians, methodologists, psychometricians and the translators. To identify any difficulties, inconsistencies or mistakes in translation, the committee explored the semantic, idiomatic and conceptual equivalence of the items and answers. Step 3 ended when the committee agreed on a penultimate version of the Italian CSQ-Revised.

Step 4. Testing the penultimate version: The CSQ-Revised was initially administered to 50 patients with chronic nonspecific pain to probe what was meant by each item and the chosen response. The expert committee re-evaluated all of the findings, although no further adjustment was required.

\section{Analytical scale properties}

All of the methodological criteria for investigating psychometric properties suggested by Terwee et al (13) were followed except for 'responsiveness' (because the present study was not longitudinal).

Acceptability: The time needed to answer the questionnaire was recorded. The patients were asked about any problems they encountered and all of the data were checked for missing or multiple responses.

Factor analysis: A CFA was performed and each of the items was specified to load on its respective subscale as originally hypothesized $(7,8)$. Model fit was assessed using statistics, a comparative fit index, a normed-fit index, root mean square error of approximation (RMSEA) and the $90 \%$ CI of RMSEA (14). Ratios of $<3$ between $\chi^{2}$ and df, comparative fit index and normed-fit index values $\geq 0.90$, and RMSEA values $\leq 0.08$ were considered to be indicative of a good fit (15).

Floor/ceiling effects: Descriptive statistics were calculated to identify floor/ceiling effects, which were considered to be present when $>15 \%$ of the subjects obtained the lowest or highest possible subscale scores (13). Reliability: This was tested by means of internal consistency, which reflects the inter-relatedness among the items (Cronbach's alpha, with a value $>0.70$ being considered acceptable), and test-retest stability, which measures reliability over time (intraclass correlation coefficient 2,1 - with good and excellent reliability being indicated by values of 0.70 to 0.85 and $>0.85$, respectively) (13). Test-retest reliability was investigated by administering the CSQ-Revised to the same subjects after seven days to avoid the natural fluctuations in symptoms associated with memory effects.

Content validity: This assessment was based on the patients' yes/no answers to questions investigating the aim of the measurement ("Do you think pain coping strategies constitute the aim of this questionnaire?"), the target population ("Do you think the items described here may be related to your chronic pain?") and the concepts being measured, with special attention being devoted to relevance ("Do you think these items are relevant to evaluate your pain coping strategies?") and completeness ("Do you think that the items presented comprehensively reflect your pain coping strategies?"). The hypotheses were considered acceptable if the rate of correct/affirmative answers was $>90 \%$ (13).

Construct validity: The extent to which an instrument's score relates to the score of the theoretical construct of another instrument as expected was investigated by means of hypothesis testing (13). It was hypothesised a priori that the CSQ-Revised maladaptive strategies (ie, Catastrophizing and Praying) would be statistically significantly and positively related to a measure of pain intensity (the 0 to 10 numerical rating scale) (16), a measure of disability (the Italian version of the Sickness Impact Profile - Roland scale) (17), and a measure of depression (the Italian version of the Center 
for Epidemiological Studies - Depression Scale) (18). It was also hypothesised that the CSQ-Revised maladaptive strategies would be statistically significantly and positively related to maladaptive strategies (Guarding, Resting, Asking for assistance) of another measure of coping (the Italian version of the Chronic Pain Coping Inventory [CPCI]) (19), and that the CSQ-Revised adaptive strategies would be statistically significantly and positively related to adaptive strategies of the CPCI (Relaxation, Task persistence, Exercise/Stretch, Seeking social support and Coping self-statements). Pearson's correlation coefficients were used.

The analyses were conducted using SPSS and AMOS (IBM Corporation, USA).

\section{Other outcome measures}

Numerical Rating Scale: This was an 11-point rating scale ranging from 0 (no pain at all) to 10 (the worst imaginable pain) (16).

Sickness Impact Profile - Roland scale: This 23-item self-report scale, which was derived from the 136-item Sickness Impact Profile questionnaire, was developed to measure disability in patients with chronic pain. Each item is dichotomous (yes/no), and the sum of the 23 scores is expressed as a total score ranging from 0 (no disability) to 23 (maximum disability as perceived by the patient) (20). The Italian version was used, which has been shown to be reliable and valid (17). Center for Epidemiological Studies - Depression scale: This 20-item self-report questionnaire was developed to assess the presence and severity of depressive symptoms. Each item is answered using a fourpoint scale $(0=$ rarely; $3=$ most of the time $)$; thus, the total score ranges from 0 to 60 (higher scores indicate worse depressive symptoms) (21). The Italian version was used, which has been shown to be reliable and valid (18).

CPCI: This 42-item self-report questionnaire asks patients to rate the frequency of their use of coping strategies during the previous week (22). There are eight subscales (Guarding, Resting, Asking for assistance, Relaxation, Task persistence, Exercise/Stretch, Seeking for social support, Coping self-statements) and each item is scored from 0 to 7, with higher scores representing greater use of coping strategies. For each subscale, the answers are summed and divided by the number of items for which a response was provided. Based on the findings of the original developers, Guarding, Resting and Asking for assistance were considered to be maladaptive strategies because they are more illness-focused, while the remaining five subscales were considered to be adaptive (23). The Italian version was introduced, which has been shown to be reliable and valid (19).

\section{RESULTS}

\section{Subjects}

A total of 380 patients were invited to participate, of whom 345 accepted, resulting in a response rate of $90.8 \%$. There were 188 females (54.5\%) and 157 males (45.5\%) with a mean age of $58.4 \pm 15.8$ years (range 21 to 88 years). The median duration of pain was 24 months (range three to 120 months). The sociodemographic characteristics of the participants are presented in Table 1 .

The clinical and sociodemographic findings are largely consistent with those found by the original developers of the CSQ-Revised, being representative of subjects with chronic pain $(6,7)$.

Translation and cross-cultural adaptation

The questionnaire was translated into Italian using a process of forward-backward translation involving four translators. It took two months to reach a culturally adapted version; all of the items were easily translated except two questions ("I try to feel distant from the pain almost as if the pain was in somebody else's body" and "I try not to think of it as my body, but rather as something separate from me"), but these difficulties were overcome by means of careful wording. A further review by experts and the testing of the penultimate version confirmed the correctness of the process of translation/back-translation and the content of the items.

The adapted questionnaire is reproduced in Appendix 1.
TABLE 1

Sociodemographic characteristics of the population $(n=345)$

\begin{tabular}{lc}
\hline Characteristic & $\mathbf{n}(\%)$ \\
\hline Marital status & \\
Unmarried & $156(45.2)$ \\
Married & $189(54.8)$ \\
Occupation & \\
Employee & $120(34.8)$ \\
Self-employed & $88(25.5)$ \\
Housewife & $47(13.6)$ \\
Pensioner & $90(26.1)$ \\
Education & \\
Primary school & $46(13.3)$ \\
Middle school & $102(29.6)$ \\
High school & $138(40.0)$ \\
University & $59(17.1)$ \\
Smoking & \\
Yes & $112(32.5)$ \\
No & $233(67.5)$ \\
Pain sites (principal) & \\
Cervical & $67(19.4)$ \\
Lumbar & $135(39.1)$ \\
Shoulder & $34(9.9)$ \\
Hip & $28(8.1)$ \\
Knee & $56(16.2)$ \\
Other & $25(7.2)$ \\
Drug use & \\
Antidepressants & $59(17.1)$ \\
Analgesics & $152(44.1)$ \\
Muscle relaxants & $37(10.7)$ \\
Nonsteroidal anti-inflammatory drugs & $97(28.1)$ \\
Hypertension & \\
Non-insulin-dependant diabetes mellitus & $111(32.2)$ \\
Heart disease & $44(12.8)$ \\
Enteric disease & $49(14.2)$ \\
None & $38(11.0)$ \\
\hline & $33(9.6)$ \\
Comorbidities (principal) & $70(20.3)$ \\
\hline
\end{tabular}

TABLE 2

Results of confirmatory factor analysis of the factorial validity of the Coping Strategies Questionnaire - Revised

\begin{tabular}{llcccc}
\hline Model & $\chi^{2} /$ df & CFI & NFI & RMSEA & 90\% Cl of RMSEA \\
\hline $\begin{array}{l}\text { Robinson } \\
\text { et al (7) }\end{array}$ & 2.97 & 0.936 & 0.908 & 0.078 & $0.072-0.083$
\end{tabular}

$\chi^{2} / d f$ Ratio between $\chi^{2}$ and df; CFI Comparative fit index; NFI Normed-fit index; RMSEA Root-mean square error of approximation

Analytical scale properties

Acceptability: All of the questions were well accepted. The CSQ-Revised was completed in $11.1 \pm 1.5 \mathrm{~min}$, and there were no missing or multiple answers. There were no problems with regard to comprehension.

Factor analysis: CFA met all of the fit criteria confirming the model on the present sample (Table 2) (7). The item-scale correlations were satisfactory (Distraction, 0.751 to 0.913 ; Catastrophizing, 0.849 to 0.891; Ignoring pain sensations, 0.821 to 0.957; Distancing from pain, 0.925 to 0.932; Coping self-statements, 0.829 to 0.926; and Praying, 0.781 to 0.982 ).

Floor/ceiling effects: No significant effects were found for any of the subscales (Table 3).

Reliability: Cronbach's alpha was acceptable for all of the subscales $(\alpha=0.914$ to 0.961$)$. Test-retest reliability was measured in all of the subjects, and the domains showed good/excellent intraclass correlation coefficients (0.850 to 0.918$)$ (Table 3$)$. 
TABLE 3

Floor/ceiling effects and reliability of the Coping Strategies Questionnaire - Revised subscales

\begin{tabular}{lcccc}
\hline Variables and subscales & Mean \pm SD & Floor/ceiling effects, \%/\% & Internal consistency, $\boldsymbol{\alpha}$ & Test-retest, ICC (95\% Cl) \\
\hline Distraction (5 items) & $16.29 \pm 7.22$ & $3.8 / 3.2$ & 0.934 & $0.904(0.853-0.939)$ \\
Catastrophizing (6 items) & $16.85 \pm 9.78$ & $7.8 / 0.9$ & 0.946 & $0.918(0.873-0.947)$ \\
Ignoring pain sensations (5 items) & $14.21 \pm 8.37$ & $6.7 / 5.8$ & 0.957 & $0.899(0.853-0.931)$ \\
Distancing from pain (4 items) & $9.38 \pm 6.36$ & $7.0 / 2.6$ & 0.961 & $0.911(0.863-0.943)$ \\
Coping self-statements (4 items) & $16.22 \pm 5.51$ & $3.2 / 11.0$ & 0.928 & $0.850(0.785-0.897)$ \\
Praying (3 items) & $11.78 \pm 4.89$ & $6.4 / 12.8$ & 0.914 & $0.851(0.768-0.906)$ \\
\hline
\end{tabular}

ICC Intraclass correlation coefficient

TABLE 4

Correlations between the Coping Strategies Questionnaire - Revised (CSQ-R) subscales and pain, disability and depression

\begin{tabular}{lccc}
\hline Variables and subscales & $\begin{array}{c}\text { Pain } \\
\text { (NRS) }\end{array}$ & $\begin{array}{c}\text { Disability } \\
\text { (SIP-Roland) }\end{array}$ & $\begin{array}{c}\text { Depression } \\
\text { (CES-D) }\end{array}$ \\
\hline CSQ-R & & & \\
Distraction (5 items) & -0.06 & 0.08 & $-0.18^{* *}$ \\
Catastrophising (6 items) & $0.27^{* *}$ & $0.36^{* *}$ & $0.49^{* *}$ \\
lgnoring pain sensations $(5$ items) & 0.07 & $-0.12^{*}$ & $-0.19^{* *}$ \\
Distancing from pain (4 items) & 0.11 & 0.11 & $-0.18^{* *}$ \\
Coping self-statements (4 items) & 0.01 & -0.08 & $-0.33^{* *}$ \\
Praying (3 items) & $0.14^{*}$ & $0.23^{* *}$ & $0.15^{*}$ \\
\hline
\end{tabular}

${ }^{*} P<0.05 ;{ }^{*} P<0.01$. CES-D Center for Epidemiological Studies - Depression Scale; NRS Numerical rating scale; SIP-Roland Sickness Impact Profile Roland Scale

Content validity: The percentage of affirmative answers was $>90 \%$ and, thus, the content of the items was considered to be adequate, appropriate for the target population, comprehensive and relevant for investigating coping strategies in this population.

Construct validity: Most of the a priori hypotheses were confirmed. As expected, Catastrophizing (from $r=0.27$ to $r=0.49$ ) and Praying (from $\mathrm{r}=0.14$ to $\mathrm{r}=0.23$ ) were statistically significantly and positively related to other similar constructs. Catastrophizing was moderately correlated with Depression ( $r=0.49 ; \mathrm{P}<0.01$ ) (Table 4).

When the coping questionnaires were compared, Catastrophizing and Praying were statistically significantly and positively related to $\mathrm{CPCI}$ maladaptive strategies (from $r=0.11$ to $r=0.26$, and from $r=0.17$ to $\mathrm{r}=0.29$ ); weaker correlations were found in the case of adaptive strategies, except when CPCI Seeking social support was compared with Catastrophizing $(\mathrm{r}=0.14)$ and Praying $(\mathrm{r}=0.26)$. Likewise, Distraction, Distancing from pain and Coping self-statements were statistically significantly and positively related to CPCI adaptive strategies (from $\mathrm{r}=0.25$ to $r=0.50$, from $r=0.23$ to $r=0.43$, and from $r=0.13$ to $r=0.54$ ) (Table 5).

\section{DISCUSSION}

The present study reports the adaptation of the CSQ-Revised and its validation in a sample of previously uninvestigated Italian patients

TABLE 5

Correlations between the Coping Strategies Questionnaire - Revised and Chronic Pain Coping Inventory (CPCI) subscales

\begin{tabular}{|c|c|c|c|c|c|c|}
\hline \multirow[b]{2}{*}{$\mathrm{CPCl}$ subscales } & \multicolumn{6}{|c|}{ Coping Strategies Questionnaire - Revised subscales } \\
\hline & Distraction & Catastrophizing & $\begin{array}{c}\text { Ignoring pain } \\
\text { sensations }\end{array}$ & $\begin{array}{c}\text { Distancing from } \\
\text { pain }\end{array}$ & $\begin{array}{c}\text { Coping } \\
\text { self-statements }\end{array}$ & Praying \\
\hline Guarding & $0.21^{* *}$ & $0.18^{* *}$ & $-0.22^{* *}$ & 0.02 & -0.05 & $0.29 * *$ \\
\hline Resting & 0.11 & 0.11 & $-0.14^{*}$ & -0.09 & -0.04 & $0.17^{* *}$ \\
\hline Asking for assistance & 0.09 & $0.26^{\star *}$ & $-0.21^{* *}$ & -0.06 & -0.09 & $0.28^{* *}$ \\
\hline Relaxation & $0.50^{* *}$ & 0.03 & 0.06 & $0.43^{* *}$ & $0.35^{\star *}$ & 0.05 \\
\hline Task persistence & $0.26^{* *}$ & $-0.20^{* *}$ & $0.55^{\star \star}$ & $0.43^{* *}$ & $0.46^{* *}$ & $-0.25^{\star *}$ \\
\hline Exercise/stretch & $0.25^{\star *}$ & 0.01 & 0.09 & $0.23^{* *}$ & $0.13^{*}$ & 0.05 \\
\hline Seeking social support & $0.35^{\star *}$ & $0.14^{*}$ & 0.06 & $0.23^{\star *}$ & $0.30^{\star *}$ & $0.26^{* *}$ \\
\hline Coping self-statements & $0.48^{* *}$ & -0.10 & $0.23^{* *}$ & $0.33^{* *}$ & $0.54^{* *}$ & 0.07 \\
\hline
\end{tabular}

with chronic pain. Analyzing the psychometric properties of an outcome measure is a continuous process that is strongly recommended to strengthen its properties and expand its applicability to specific populations and contexts (24). Our findings provide further evidence regarding the relationships between CSQ-Revised and CPCI, two widely used questionnaires that assess coping strategies in individuals with chronic pain.

The meaning of the original items was adequately captured by the idiomatic translation of the CSQ-Revised. The difficulties encountered by the translators were overcome by means of careful wording. The questionnaire was acceptable and easily understood, and could be self-administered in approximately $10 \mathrm{~min}$. It responded satisfactorily to the requirements of relevance and completeness, and appeared to be fully applicable to everyday clinical practice. No significant floor/ ceiling effects were found, which suggests the scale correctly assesses its construct.

The factorial structure of the CSQ-Revised was confirmed, and the satisfactory item-scale correlations enabled us to include all of the 27 items, as originally proposed (7). This model adequately fits the data obtained from our sample, which suggests that coping strategies can be thoroughly described as a process with six components. French researchers have also performed a CFA using the CSQ-Revised, and achieved satisfactory results consistent with our findings and those of Riley and Robinson $(8,9)$.

Our internal consistency was satisfactory, thus confirming the extent to which the items assessed the same construct. Our estimates $(\alpha=0.72$ to 0.86$)$ and the French adaptation $(\alpha=0.57$ to 0.83$)(7,9)$.

The CSQ-Revised also showed satisfactory test-retest reliability in the investigated population and context; however, this psychometric property was not tested in the original and other adapted versions of the CSQ-Revised and, thus, no comparisons are possible.

Consistent with the English findings (8), our estimates of construct validity highlighted the adaptive (ie, Distraction, Ignoring pain sensations, Distancing from pain and Coping self-statements) and maladaptive properties (Catastrophizing and Praying) of most of the subscales $(4,7,25)$.

The correlations between the CSQ-Revised and the CPCI contributed further evidence of the adaptive and maladaptive strategies investigated by both measures. Our findings also suggest that the were higher than that of the developers of the CSQ-Revised

${ }^{*} P<0.05 ;{ }^{* *} P<0.01$. 
CSQ-Revised and CPCI have different constructs, thus highlighting their distinctive contribution to multidisciplinary pain programs and confirming the intent of the original developers of the CPCI to create a questionnaire that investigated previously ignored coping strategies (22). As observed in previous studies (26), exceptions were the correlations between CPCI-Task persistence and CSQ-Ignoring pain sensations, CSQ-Distancing from pain and CSQ-Coping selfstatements; between CPCI-Relaxation and CSQ-Distraction and CSQ-Distancing from pain; and between CPCI-Coping self-statements and CSQ-Distraction and CSQ-Coping self-statements, which suggests that these constructs likely overlap in scale content and require further investigations.

There were several limitations to the present study. First, its crosssectional design means that significant correlations should not be confused with causal effects. Second, the relationships between selfreported beliefs and objective measures of coping, such as behavioural observations or reports of cognitive coping during structured or standardized situations, were not considered because only self-administered measures were used. Third, additional studies of the properties of CSQRevised using modern test theory methods, such as Rasch measurement theory or item response theory, are recommended because only classical test theory psychometric properties were evaluated.

\section{CONCLUSION}

The Italian version of the CSQ-Revised confirmed the factor structure of the original English version and showed good psychometric properties. It can be recommended for use in chronic pain research and multidisciplinary pain assessments.

ACKNOWLEDGEMENTS: The authors thank Kevin Smart for his help in preparing the English version of the manuscript.

DISCLOSURES: The authors have no conflicts of interest to declare.

IRB APPROVAL: The authors' Institutional Review Board approved the study, which was conducted in accordance with ethical and humane principles of research.

\section{APPENDIX 1}

CSQ-R-I, Coping Strategies Questionnaire - Revised: Italian Version

Le persone sviluppano strategie per fronteggiare e gestire il dolore che sentono. Queste strategie includono dire cose a noi stessi quando si prova dolore o quando si svolgono le attività quotidiane. Di seguito è riportato un elenco di cose che le persone hanno raccontato di fare quando provano dolore. Per cortesia, per ogni attività descritta indichi utilizzando la scala sotto riportata in che misura si sente coinvolto/a quando prova dolore.

\section{REFERENCES}

1. Reyes Gibby CC, Aday L, Cleeland C. Impact of pain on self-rated health in community-dwelling older adults. Pain 2002;95:75-82.

2. Jensen MP, Turner JA, Romano JM. Changes in beliefs, catastrophizing and coping are associated with improvement in multidisciplinary pain treatment. J Consult Clin Psychol 2001;69:655-62.

3. Rosenstiel AK, Keefe FJ. The use of coping strategies in chronic low back pain patients: Relationship to patient characteristics and current adjustment. Pain 1983;17:33-44.

4. Swartzman LC, Gwadry FG, Shapiro AP, Teasell RW. The factor structure of the Coping Strategies Questionnaire. Pain 1993;57:311-6.

5. Tuttle DH, Shutty MS, DeGood DE. Empirical dimensions of coping in chronic pain patients: A factorial analysis. Rehab Psychol 1991;36:179-87.

6. Lawson K, Rossier K, Keefe FJ, Turner JA. Dimensions of painrelated cognitive coping: Cross-validation of the factor structure of the Coping Strategies Questionnaire. Pain 1990;43:195-204.

7. Robinson ME, Riley JL, Myers CD, et al. The Coping Strategies Questionnaire: A large sample item level factor analysis. Clin J Pain 1997;13:43-9.

$\begin{array}{lllcrrr}0 & 1 & 2 & 3 & 4 & 5 & 6 \\ \text { non lo } & & \begin{array}{l}\text { ogni tanto } \\ \text { lo faccio }\end{array} & & & \text { lo faccio } \\ \text { faccio mai } & & & & \end{array}$

Strategie di coping

Distrarsi $(1,2,3,4,5): \ldots . / 30$

Catastrofismo $(17,18,19,20,21,22):$..../36

Ignorare le sensazioni dolorose: $(6,7,10,11,12): \ldots . / 30$

Prendere le distanze dal dolore $(13,14,15,16):$.../24

Strategie di auto-affermazione $(8,9,26,27): \ldots . / 24$

Pregare $(23,24,25): \ldots / 18$

\section{Domande}

Punteggi
1) Immagino cose che mi fanno piacere
2) Immagino persone con cui amo divertirmi
3) Ripenso a piacevoli esperienze trascorse
4) Faccio cose che mi gratificano come guardare la televisione o ascoltare la musica
5) Cerco di pensare a qualcosa di piacevole
6) Cerco di andare avanti come se niente fosse
7) Non presto attenzione al dolore
8) Dico a me stesso che il dolore non deve interferire con ciò che faccio
9) Anche se provo dolore cerco di andare avanti
10) Non penso al dolore
11) Ignoro il dolore
12) Fingo che il dolore non ci sia
13) Immagino che il dolore sia estraneo al mio corpo
14) Fingo che il dolore non mi appartenga
15) Cerco di estraniarmi dal dolore, come se appartenesse a qualcun altro
16) Cerco di pensare che il dolore non appartenga al mio corpo ma che sia qualcosa di estraneo
17) Ho la sensazione di non poter più sopportare il dolore
18) Ho la sensazione di non riuscire ad andare avanti
19) Sono preoccupato riguardo a quando finirà il dolore
20) Ho la sensazione che non valga la pena vivere
21) II dolore è terribile e ho la sensazione che mi travolga
22) II dolore è terribile e ho la sensazione che non migliorerà mai
23) Prego Dio che il dolore non duri a lungo
24) Supplico che il dolore finisca
25) Confido nella fede in Dio
26) Dico a me stesso che posso superare il dolore
27) Dico a me stesso di avere coraggio e di andare avanti nonostante il dolore

8. Riley J, Robinson ME. CSQ: Five factors or fiction? Clin J Pain 1997;13:156-62.

9. Irachabal S, Koleck M, Rascle N, Bruchon-Schweitzer M. Pain coping strategies: French adaptation of the Coping Strategies Questionnaire (CSQ-F). L'Encephale 2008;34:37-43.

10. Jensen IB, Linton SJ: Coping Strategies Questionnaire (CSQ): Reliability of the Swedish version of the CSQ. Scand J Behav Ther 1993;22:139-45.

11. Verra ML, Angst F, Lehmann S, Aeschlimann A. Translation, crosscultural adaptation, reliability, and validity of the German version of the Coping Strategies Questionnaire (CSQ-D). J Pain 2006;7:327-36.

12. Beaton DE, Bombardier C, Guillemin F, Ferraz MB. Guidelines for the process of cross-cultural adaptation of self-report measures. Spine (Phila Pa 1976) 2000;25:3186-9.

13. Terwee CB, Bot S, de Boer MR, et al. Quality criteria were proposed for measurement properties of health status questionnaires. J Clin Epidemiol 2007;60:34-42.

14. Browne MW, Cudeck R. Alternative ways of assessing model fit. In: Bollen KA, Long JS, eds. Testing Structural Equation Models. Newbury Park: Sage, 1993:136-62. 
15. Hu LT, Bentler PM. Cut-off criteria for fit indexes in covariance structure analysis: Conventional criteria versus new alternatives. Structural Equation Modeling 1999;6:1-55.

16. Huskinson EC. Measurement of pain. Lancet 1974;2:1127-31.

17. Monticone M, Baiardi P, Nava T, Rocca B, Foti C. The Italian version of the Sickness Impact Profile-Roland Scale for chronic pain: Cross-cultural adaptation, reliability, validity and sensitivity to change. Disab Rehabil 2011;33:1299-305.

18. Fava GA. Assessing depressive symptoms across cultures: Italian validation of the CES-D self-rating scale. J Clin Psychol 1983;39:249-51.

19. Monticone M, Ferrante S, Giorgi I, Galandra C, Rocca B, Foti C. Development of the Italian version of the 42 -item Chronic Pain Coping Inventory, CPCI-I: Cross-cultural adaptation, factor analysis, reliability and validity. Qual Life Research 2013;22:1459-65.

20. Jensen MP, Strom SE, Turner JA, Romano JM. Validity of the Sickness Impact Profile Roland as a measure of dysfunction in chronic pain patients. Pain 1992;50:157-62.
21. Radloff LS, Locke BZ. The Community Mental Health Assessment Survey and the CES-D scale. In: Weissman M, Myers J, Ross C, eds. Community Surveys. Piscataway: Rutgers University Press, 1977:177-189.

22. Romano, JM, Jensen, MP, Turner, JA. The Chronic Pain Coping Inventory-42: Reliability and validity. Pain 2003;104:65-73.

23. Jensen MP, Turner JA, Romano JM, Strom SE. The Chronic Pain Coping Inventory: Development and preliminary validation. Pain 1995;60:203-16.

24. de Vet HC, Terwee CB, Mokkink LB, Knol DJ. Measurement in Medicine. A Practical Guide. Cambridge: Cambridge University Press, 2011.

25. Tan G, Jensen MP, Robinson-Whelen S, Thornby JI, Monga TN. Coping with chronic pain: A comparison of two measures. Pain 2001;90:127-33.

26. Hadjistavropoulos HD, MacLeod FK, Asmundson GJ. Validation of the Chronic Pain Coping Inventory. Pain 1999;80:471-81. 


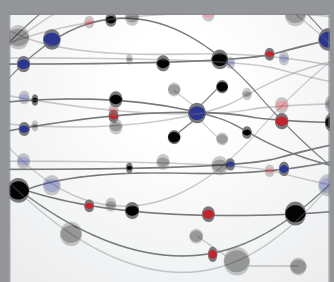

The Scientific World Journal
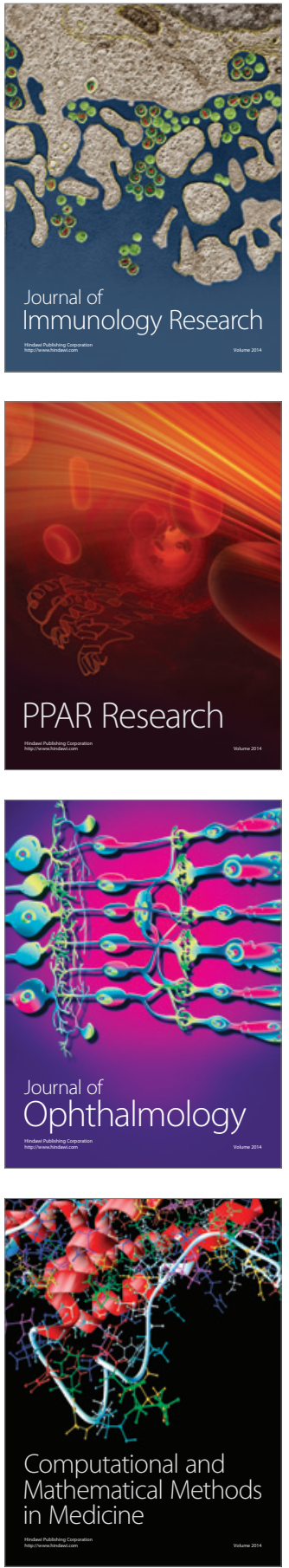

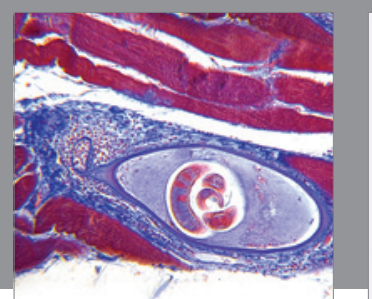

Gastroenterology Research and Practice

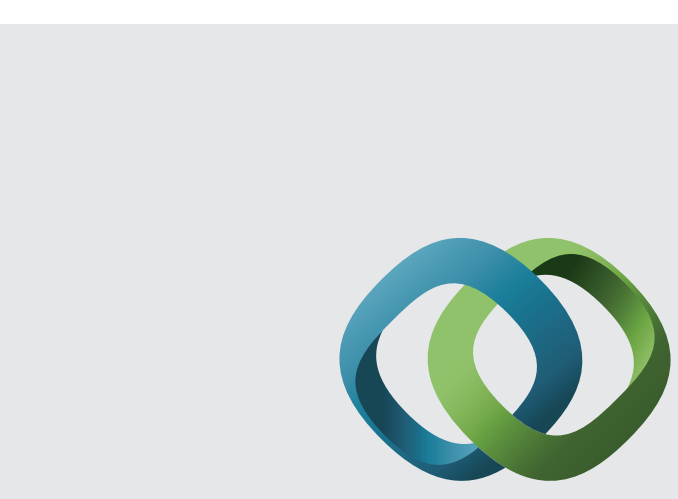

\section{Hindawi}

Submit your manuscripts at

http://www.hindawi.com
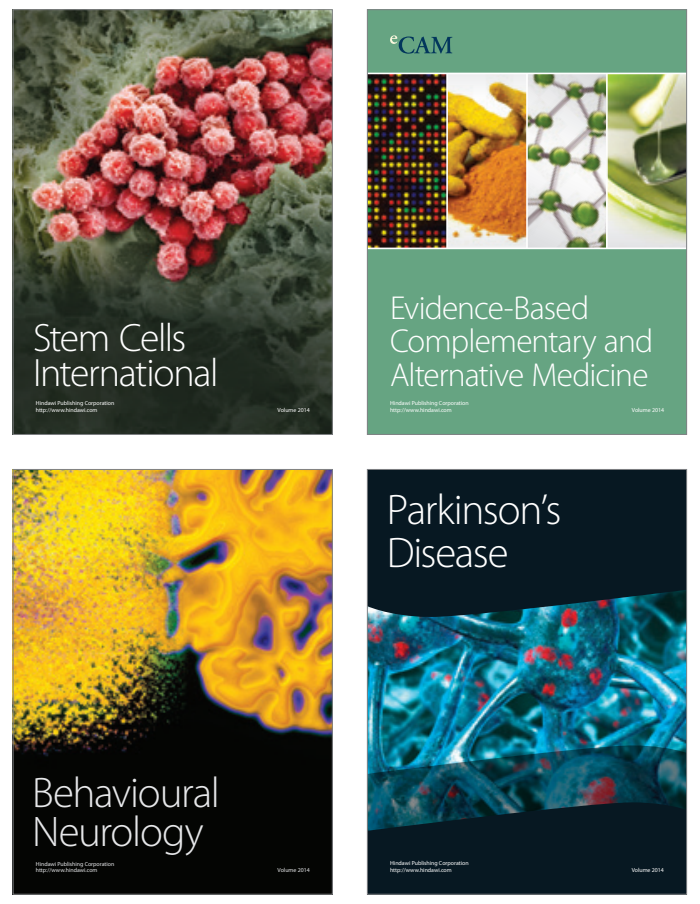
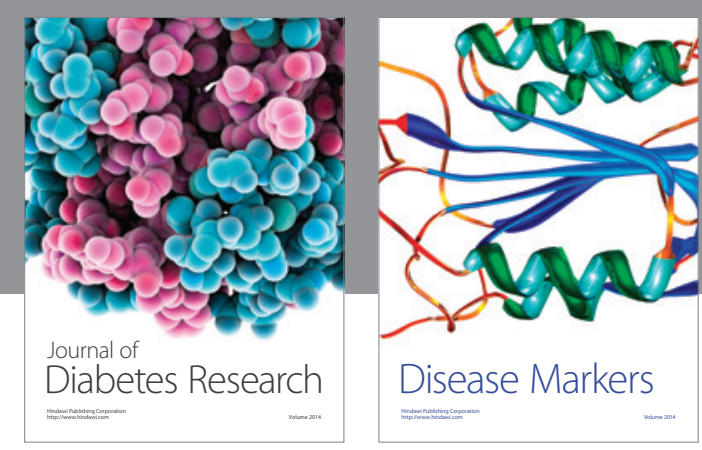

Disease Markers
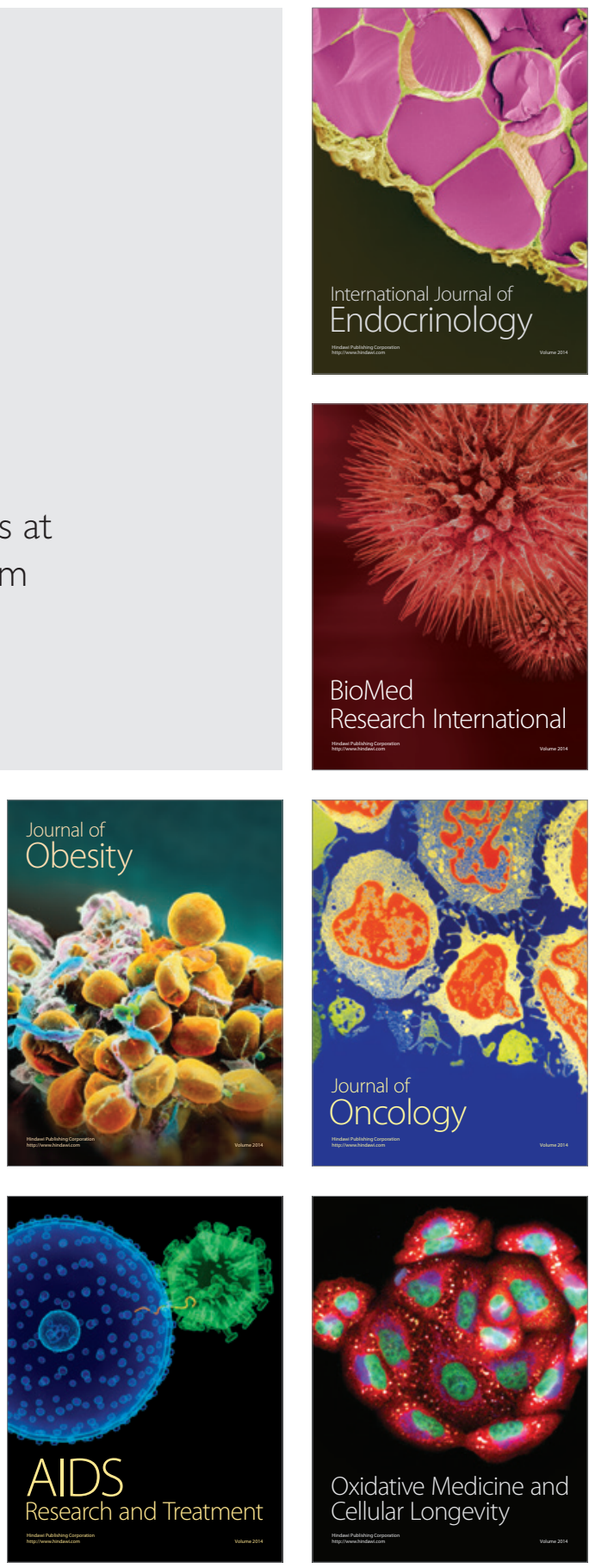